\title{
Integrated nutrient transport modelling with respect to the implementation of the European WFD: The Weiße Elster Case Study, Germany\#
}

\author{
Michael Rode ${ }^{1 *}$, Bernd Klauer ${ }^{2}$, Daniel Petry ${ }^{4}$, Martin Volk ${ }^{3}$, Gerald Wenk ${ }^{1}$ and Dierk Wagenschein ${ }^{1}$ \\ UFZ-Helmholtz Centre of Environmental Research, Germany: \\ ${ }^{1}$ Department of Aquatic Ecosystem Analysis and Management, Brueckstrasse 3a, 39114 Magdeburg, Germany \\ ${ }^{2}$ Department of Economics, PO Box 500 136, 04301 Leipzig, Germany \\ ${ }^{3}$ Department of Landscape Ecology, PO Box 500 136, 04301 Leipzig, Germany \\ ${ }^{4}$ Global Water System Project, International Project Office, Walter-Flex-Str. 3, 53113 Bonn, Germany
}

\begin{abstract}
The goal of the European Water Framework Directive (WFD) is to protect and enhance the status of aquatic and terrestrial ecosystems. To reach this objective an integrated methodology for the implementation of the WFD is essential. The methodology presented was developed within an interdisciplinary research project on the highly polluted 4th order Weiße Elster River basin, a large subcatchment of the Saale basin (Germany), which is part of the UNESCO-IHP HELP program. The project focuses on nutrient management in order to achieve a good ecological status of surface waters. The paper focuses on an integrated modelling of nitrogen transport and comprises combined terrestrial and in-stream transport processes. The mitigation of diffuse and point sources pollution is thereby essential to meet the environmental objectives. Land-use scenarios on both organic farming systems and best management practices were analysed and compared with different strategies to reduce point source. The results show that the possible reduction of nitrogen inputs from point sources is much lower compared to the reduction of diffuse inputs from agricultural land use. The results on in-stream nitrogen transformation show that different morphological factors influence the nitrogen retention considerably. The potential of management measures to reduce nitrogen loads by river restoration measures seems to be limited. This is caused by infrastructural facilities that restrict attaining a natural state of river morphology.
\end{abstract}

Keywords: river basin management, nutrient transport, river restoration, SWAT, WASP

\section{Introduction}

The European Water Framework Directive (WFD) states the goal that all waters in the European Union should reach a good status by 2015 (European Parliament, 2000). In order to achieve this goal the member states need to set up river basin districts, each one having a management plan that includes a program of measures which will achieve good status in the most costeffective manner. This involves an evaluation of different policy measures, both with respect to the effects of nutrient reducing measures as well as its economic consequences, upon which policy makers can base their decisions. The overall objective of the case study is to develop a decision support methodology for the implementation of the Programmes of Measures (PoM) according to the WFD with special focus on the impact analysis including nutrient reduction (contribution to the environmental objectives) and economic analysis (costs of the measure). The methodological approach for decision support structures the implementation of the PoM into six phases (see Fig. 1).

The paper concentrates on the impact analysis comprising the evaluation of management scenarios to reduce nitrogen loadings using the Weiße Elster catchment as a case study. The catch-

Revised paper. Originally presented at the symposium 'HELP in Action: Local Solutions to Global Water Problems - Lessons from the South' which was held at the Emperor's Palace, Johannesburg, South Africa from 4 to 9 November 2007.

* To whom all correspondence should be addressed.

真

+49 (0)391 8109650; fax: +49 (0)391 8109699;

e-mail: michael.rode@ufz.de

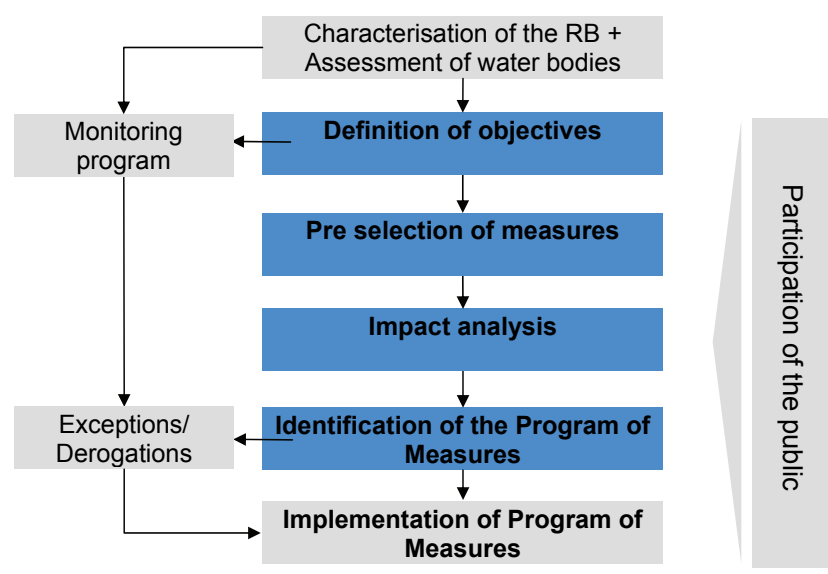

Figure 1

Structure of the Program of Measures (PoM) with steps in the planning process $(R B=$ river basin)

ment is part of the Elbe basin in Germany. The scenario analysis is carried out using appropriate hydrological nutrient transport and river water quality models. Specific objectives are to:

- Assess the impact of different agricultural management practices on the reduction of nitrogen yield for different baseline and management scenarios using the Soil Water Assessment Tool (SWAT)

- Evaluate the importance of different river restoration measures with respect to nutrient transport and assess model uncertainties using the WASP5 river water quality model. 


\section{Methods}

\section{Case study}

\section{Catchment characteristics}

The Weiße Elster River basin is a subcatchment of the Saale River which is the second largest tributary of the Elbe River. The catchment area is about $5300 \mathrm{~km}^{2}$ and is mainly situated in the German States of Sachsen (Saxony), Thüringen (Thuringia) and Sachsen-Anhalt (Saxony-Anhalt). The river originates from the Erzgebirge (Ore Mountains) in the Czech Republic, is 250 $\mathrm{km}$ long and has a mean discharge of $26 \mathrm{~m}^{3} / \mathrm{s}$ (gauging station Oberthau). The river channel structure is very diverse with nearnatural stretches as well as concrete-lined segments.

The land use (Fig. 2) in the basin is dominated by agricultural activities ( $43 \%$ cropland, $16 \%$ pasture) especially in the lower part, and forest (21\%), mainly in the upper part. The upper part of the basin is mountainous characterised by steep slopes and narrow valleys with hardly any floodplains and scarce groundwater resources. The geology is characterised by igneous and metamorphic rocks and consolidated tertiary rocks (sandstone). The lower part of the basin is situated in the lowlands and mainly consists of Pleistocene coverage. Precipitation varies between $500 \mathrm{~mm}$ in the northern part of the basin (lowlands) to 1000 $\mathrm{mm}$ in the southern part (mountains). The annual runoff varies approximately between 50 and $600 \mathrm{~mm}$.

Main field crops are grains and root crops in the northern part of the catchment and forage crops in the southern more hilly parts of the basin. Livestock in the area consists mainly of cattle. Settlements, industrial areas, and infrastructure account for $16 \%$ of the land use with Leipzig and Halle being major cities located in the catchment. The area south-west of Leipzig is characterised by active and reclaimed open pit mines. The implementation of the WFD for the Weiße Elster River is coordinated by the Saale Basin Co-ordination Group which is formed by representatives of the State ministries of environment (Thuringia, Saxony, and Saxony - Anhalt, Bavaria and Lower Saxony).

Meteorological data were made available from the German national meteorological service. There are about 60 precipitation and 11 climate stations in and around the Weiße Elster basin. Daily data were made available for most of the precipitation gauging stations, while six-hourly or hourly data were available for the climate stations. Time series data were collected from 1990 to 2003. Daily water level measurements were made available for about 20 gauging stations in the Weiße Elster catchment. These stations are managed by the environmental agencies of the Federal States. Time series of water level and discharge data were used from 1990 to 2002 . There are about 20 water quality monitoring stations in the Weiße Elster catchment. But measurements were taken only 1 to 2 times per month. An extensive number of physico-chemical properties were measured. Data of water extraction and discharge to the river were mostly taken as permitted values.

A digital elevation model was made available at $50 \mathrm{~m}$ resolution. Land use information was derived from Landsat imagery at a spatial resolution of $30 \mathrm{~m}$ for 1989 and 1999. Furthermore a detailed biotope map derived from aerial photography was used. Several soil maps were made available in digital format with spatial resolutions of 1:1000 000 and 1: 200000 .

\section{Description of problems}

Water quantity and quality are closely related to the various economic activities in the river basin. Agriculture, urbanisation as well as open pit mining have contributed to the chemical and

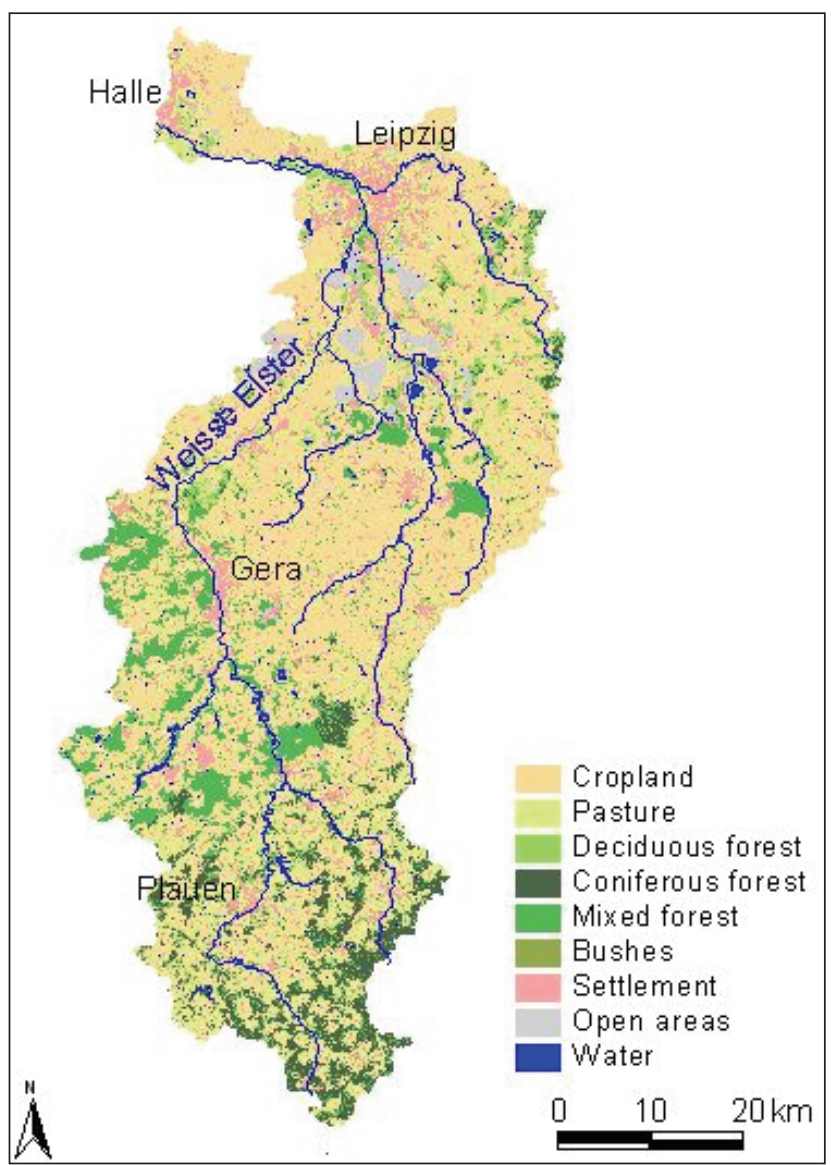

Figure 2

Land use in the Weiße Elster Catchment

biological pollution of the Weiße Elster River. Most of the Weiße Elster River has been classified as moderately polluted with some segments as critically polluted (classification according to German water quality standards). Main problems are nutrients $(\mathrm{N} \& \mathrm{P})$ with high ammonium concentrations in some river reaches. Also, salt concentrations (esp. sulphate) are quite high due to open-pit mining and other industrial activities. However, the sulphate loads are not considered to be ecologically relevant. It is not yet clear whether the discontinuation of mining activities and flooding of open-pit mines will alter salt concentrations of the Weiße Elster. Although water quality has substantially improved in the last few years, a comprehensive remediation programme is necessary to meet the WFD targets.

Nutrient concentrations in the Weiße Elster River and its major tributaries given as 90-percentile of concentrations (2001) range between 6.1 and $13.0 \mathrm{mgN} / \ell$ and 0.14 and $0.74 \mathrm{mgP} / \ell$. Diffuse sources have been estimated to have contributed to the overall nutrient load by $84 \%$ (nitrogen) and $65 \%$ (phosphorus). High $\mathrm{NH} 4$ and PO4 concentrations at the lowland river reaches are caused by high sewage inputs from urban areas. Main water uses conflicting with water quality targets according to WFD are:

- Agriculture vs. water quality: agriculture contributes to a great extent to diffuse pollution load. This load conflicts with ecosystem restoration and impairs drinking water quality.

- Industrial and municipal discharge vs. water quality: other important reasons for the poor water quality of the Weiße Elster are point pollution from industrial and municipal effluents, considerable water abstraction for industrial use and flooding of mining lakes. 


\section{Model set-up}

The evaluation of management measures is carried out with regard to improvement of water quality. Two models were applied: the integrated Soil and Water Assessment Tool (SWAT) which simulates the water balance and nitrogen transport, and the Water Quality Analysis Simulation Program (WASP5) which simulates the hydrodynamic and in-stream transformation processes. Water and nitrogen transport of the entire Weiße Elster basin is simulated with the Soil and Water Assessment Tool (SWAT). SWAT is a deterministic continuous process-based model coupling hydrological, biogeochemical, and ecological processes at the river basin-scale (Arnold et al., 1994; Krysanova and Haberlandt, 2002). According to the stepwise approach the simulation first focuses on the hydrological cycle and secondly on the transport of nitrogen.

The Weiße Elster catchment was divided into 108 subcatchments based on the hydrological characteristics. SWAT model calibration and validation was carried out using time series data from 1991 to 2000. After parameter sensitivity evaluation, the calibration was carried out manually using the most important parameters. A detailed sensitivity analysis of the SWAT model can be found in Van Griensven et al. (2002). The calibration runs of the hydrological model were assessed by visual comparison of the simulated and the observed hydrographs and objective criteria (e.g. Pearson's Product-Moment Correlation Coefficient, the coefficient of determination, the Nash \& Sutcliffe coefficient of efficiency, yearly absolute volumetric error measures). They quantify the degree of agreement between the observed and simulated values.

The water quality model WASP5 (Water Quality Analysis Simulation Program) is a one- to three-dimensional numerical model and includes a deterministic approach to describe the hydrodynamics and the turnover of nutrients and chemicals in water column and sediments. It was developed at the U.S. Environmental Protection Agency (Ambrose et al., 1993). The WASP5 modelling system consists of three stand-alone computer programs, that can be run in conjunction or separately: DYNHYD is a hydrodynamic model, which is based on the Saint Venant equations; EUTRO can be used to model oxygen depletion, eutrophication, and nutrient enrichment in the river; and TOXI simulates the sediment transport and the fate of toxic inorganic and organic chemicals. In this study a modified version of DYNHYD (Warwick, 1999) was used which allows the consideration of weirs. Also an extended version of EUTRO was applied (Shanahan and Alam, 2001), which consists of nine model variables: biomass of phytoplankton (PHYT), biomass of periphyton (PERI), dissolved oxygen (DO), biochemical oxygen demand (BOD), ammonia nitrogen $\left(\mathrm{NH}_{4}\right)$, nitrate nitrogen $\left(\mathrm{NO}_{3}\right)$, organic nitrogen $(\mathrm{ON})$, phosphate $\left(\mathrm{PO}_{4}\right)$ and organic phosphorus (OP). The complex system of these variables is described by several processes, such as growth and decay of the autographs, settling, re-aeration, sediment oxygen demand, nitrification, denitrification and mineralisation. In total up to 59 temperature coefficients and kinetic parameters are used. Additional information on latest model modification can be found in Wagenschein and Rode (2008). The main advantage of WASP5 compared to other water quality models is its flexibility as it offers a possibility to build one-, two- or three-dimensional networks. Complex aquatic systems can be subdivided into lateral, vertical and longitudinal segments. Another advantage is the freely available source code of WASP5, which makes it possible to implement additional processes and components in the modelling system.
The Weiße Elster River water quality model set-up consists of 872 river cross-sections. Uncertainty analysis based on the Monte Carlo approach was carried out for the calibrated model. Discharge and nutrient load input data were obtained from the water authorities and additional measurement campaigns. Point source data from sewage systems were directly used as inputs into the WASP5 model for the Weiße Elster River. Frequentist and Bayesian techniques are the most common methods for model or parameter identification (Omlin and Reichert, 1999). In this study frequentist analysis was used as much less time was needed. It comprises two steps:

- Assessment of parameter identifiability by sensitivity analysis and calculation of compensation measures (Reichert and Vanrolleghem, 2001)

- Calibration of the WASP5 model with the automatic parameter estimation tool PEST (Doherty, 2004) using the 8 most important parameters (see also Wagenschein and Rode, 2008).

All other parameters were defined using literature values. A detailed sensitivity analysis can be found in Wagenschein (2006). During the calibration process, PEST allows quantification of $95 \%$ parameter confidence limits based on the solution of the covariance-matrix.

As criteria to measure the model performance the Index of Agreement $d$ (Willmott, 1982) and the Nash-Suttcliffe-criteria $E$ (Nash and Suttcliffe, 1970) were used. The $d$ includes values of between 0 and 1 , with values close to 1 indicating a good agreement of the model results to the measured data. The coefficient of efficiency (E) was selected because it is dimensionless and is easily interpreted. When the measured variable is simulated exactly by the model, $\mathrm{E}$ equals 1 . If $\mathrm{E}<0$, the predictive precision of the model is lower than when the mean of the values measured is used.

\section{Scenario analysis}

The validated SWAT model provided the basis for the analysis of the status quo and land-use management scenarios for the reduction of nitrogen inputs in the Weiße Elster catchment. The following land-use management measures were analysed:

- Different shares of organic farming on total arable land, scenarios amount to the shares of $5 \%, 10 \%, 20 \%$, and $30 \%$ of organic farming

- Land-use distributions in 2010 according to the present agricultural policy expectations (RAUMIS 2010; Gömann et al., 2003)

- Land-use distribution in 2010 according to a liberalisation of the agricultural market (RAUMIS-TLB; Gömann et al., 2003).

Additionally the effect of three river restoration scenarios on the nutrient concentration is investigated:

- River restoration Scenario 1 analyses measures of the river maintenance program of the water authorities on a $57.3 \mathrm{~km}$ river reach in the lower part of the Weiße Elster River. It consists of local extensions of river width, local increase of river bottom roughness, additional shadowing by riparian vegetation and the removal of one weir.

- River restoration Scenario 2 assumes natural morphological conditions in all reaches of the river, which are not restricted by roads, railways or urban areas. These unrestricted reaches comprise $37.5 \%$ of the study river section. Natural conditions were defined using morphological parameters of 
undisturbed reference sites. Natural sites were defined by a sinuosity value of 1.3 for river section upstream of the City of Zeitz and 1.7 for river sections downstream of Zeitz. Reaches with modified river structure show lower values due to straightening of river meanders. Hence, this scenario leads to higher sinuosity in the study reaches and an increase of flow length of $16.4 \%$. The river cross-sections in natural conditions are defined by a mean width of $32 \mathrm{~m}$ and a mean depth of $1.1 \mathrm{~m}$ for the upper part of the river section upstream of Zeitz. Downstream of Zeitz the mean width of $24 \mathrm{~m}$ and the mean depth of $1.5 \mathrm{~m}$ was used. Mannings coefficient was taken as 0.033 for the upper part and 0.035 for the lower part of the river reach according to Pottgiesser and Halle (2004).

- River restoration Scenario 3 is a hypothetical scenario, which assumes morphological reference conditions for the whole river section. Natural mean values of sinuosity, w/dratio and Mannings coefficient were defined according to Scenario 2. Additionally, all weirs were removed from the hydrodynamic model and constant channel slopes were assumed for these river reaches.

The land use RAUMIS 2010 and RAUMIS-TLB scenarios reflect baseline conditions under different agricultural policy conditions. The RAUMIS model is an agricultural market model which is able to consider the impact of the world market as well as the European agricultural market on the agricultural sector in Germany. RAUMIS allows calculating crop rotations, the share of arable land and pasture and associated crop yields as well as livestock in the county level (Gömann et al., 2003). Main differences between these scenarios compared to status quo are a moderate reduction of $9 \%$ (RAUMIS 2010) to an extreme reduction of $43 \%$ of agricultural land use (RAUMIS-TLB) in the Weiße Elster catchment. The county level land use data have been disaggregated on the 50 meter raster level of the original land use map according to potential crop yields of the arable land (Marks et al., 1992). Potential crop yield was calculated according to the site characteristics, such as soil, relief, water balance, climate and erosion risk. Agricultural areas with low potential crop yield are assumed to convert to fallow. Only areas with a minimum size of 1 ha were considered. The new land use maps of the two baseline scenarios have been used as input for the SWAT scenarios simulation.

Simulation of different shares of conventional and organic farming on total agricultural land use in the catchment is based on randomly distributed changes in land use. Organic farming is represented in the SWAT model by modifying crop rotations and fertiliser application. SWAT simulates the changes in nitrogen loads according to the baseline and management scenarios for every of the 108 subcatchments in the Weiße Elster basin. The scenario analysis is carried out using time series data from 1976-2000 for the calculation of long-term mean yearly nitrogen loads.
The effect of river morphology on the nitrogen retention was analysed in a first step by sensitivity analyses with the WASP5 model. The Mannings coefficient (as a measure for river bottom roughness), the width/depth-ratio (w/d-ratio) and the sinuosity were sequentially varied by $\pm 10 \%$. The effect on the model output variables is expressed by the elasticity $\varepsilon$, which can be approximated by:

$$
\varepsilon \approx \frac{\Delta x}{\Delta \Theta} \frac{\Theta}{x}=\frac{x_{i}-x_{0}}{((1+p / 100) \Theta-\Theta} \frac{\Theta}{x_{0}}=\frac{x_{i}-x_{0}}{p / 100 x_{0}}
$$

where:

$x_{0}$ and $x_{i}$ are the output variables before and after variation of parameter $\Theta$ by the value $p(10 \%)$

The influence of the morphological parameters "Mannings n", width/depth ratio and sinuosity on nitrogen concentrations were compared with the influence on other model variables like organic phosphorus (OP), ortho phosphorus $\left(\mathrm{PO}_{4}-\mathrm{P}\right)$, oxygen $\left(\mathrm{O}_{2}\right)$, phytoplancton (PHYT), periphyton (PERI), and biological oxygen demand (BOD). Elasticity $\varepsilon$ of the selected morphological parameters was determined for each model variable.

\section{Results}

\section{Model calibration}

Calibration of the SWAT model shows good results for most of the discharge gauge stations with Nash and Sutcliffe values between 0.5 and 0.8 . Lowest values of efficiency for model calibration are achieved in subcatchments with considerable impact of open pit mining. Due to these limitations the visual comparison of model predictions and observations is important. An example of the results of the hydrological model calibration is given in Fig. 3 for gauging station Zeitz with a catchment size of $2476 \mathrm{~km}^{2}$ and a Nash and Sutcliff coefficient of 0.7. Also the visual inspection shows a good agreement of measured and simulated discharge.

\begin{tabular}{|c|c|c|c|c|c|c|c|c|c|c|}
\hline \multicolumn{11}{|c|}{$\begin{array}{l}\text { TABLE } 1 \\
\text { Index of Agreement }(d) \text { and Nash-Suttcliffe-Criteria }(E) \text { for the calibration runs } \\
\text { (after Wagenschein and Rode, 2008) }\end{array}$} \\
\hline Criteria & $\begin{array}{l}\text { Number of } \\
\text { values } n\end{array}$ & PHYT & PERI & DO & CBOD & $\mathrm{NH}_{4}$ & $\mathrm{NO}_{3}$ & ON & $\mathrm{PO}_{4}$ & OP \\
\hline$d$ & $14(* 8)$ & 0.98 & $0.72 *$ & 0.99 & 0.99 & 0.87 & 0.99 & 0.97 & 0.98 & 0.95 \\
\hline$E$ & $14(* 8)$ & 0.86 & $-1.43^{*}$ & 0.43 & 0.86 & 0.30 & 0.89 & 0.17 & 0.61 & 0.60 \\
\hline
\end{tabular}

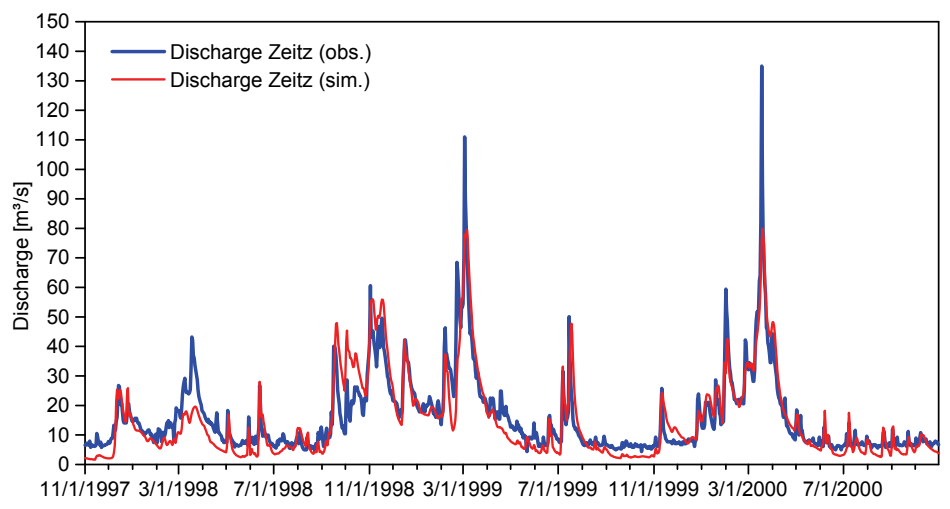

Figure 3

Measured and simulated daily discharge of the Weiße Elster River at gauging station Zeitz (calibration mode) 
The calibration of the hydrological model serves as basis for the calibration of the nitrogen model. The calibration results for nitrogen loads of a 10-year period (1989-1998) are reasonable with Nash and Sutcliffe values of 0.47 for gauging station Läwitz $\left(100 \mathrm{~km}^{2}\right)$ and 0.48 for gauging station Gera-Langenberg (2 $167 \mathrm{~km}^{2}$ ). River water quality simulations carried out with the WASP5 model are shown in Table 1 for selected model variables. Nitrate nitrogen is simulated in the calibration run with a d-value of 0.99 and an E-value of 0.89. In contrast, the fit of ammonia nitrogen is unsatisfactory. This is caused by low concentrations during the observed time periods, which amounts less than $0.03 \mathrm{mg} / \ell$. While simulated phytoplankton values show a good agreement with measured values, periphyton biomass shows larger errors. Due to the large variability of periphyton biomass the small number of periphyton measurements does not represent the mean value of a model segment. Figure 4 shows the calibrated chlorophyll-a concentrations for the selected river reach of the Weiße Elster for the 2nd September 2003 and 3rd August 2004. Measured and simulated chlorophyll-a concentrations show a good agreement.

The calibrated model was validated for a half-year period in 2001. The results were compared with the data of the monitoring programme conducted by the official water authorities. For nitrate nitrogen the modelling results are reasonable with NS value of 0.56 , although measured values are slightly underestimated. For ammonia there are larger deviations with a NS value of 0.14 , which are mainly caused by temporal variability of the ammonia inputs by sewage plants. Measured phytoplankton concentrations are well represented by the measured values. Inorganic phosphorus is also slightly underestimated by the model.

\section{Analyses of land use scenarios and agricultural management measures}

The yearly nitrogen loads from the scenario analyses for the time series from 1991-2000 at the discharge gauging station Gera-Langenberg in the middle part of the Weiße Elster catchment is shown in Fig. 5. The figure shows only small differences between the selected shares of organic farming, the baseline scenario business as usual (RAUMIS 2010) and the status quo. All scenarios lead only to a small reduction in the nitrogen load with an increased share of organic farming at total agricultural land. However, even a share of $30 \%$ organic farming does not reduce the nitrogen load substantially. Reduced nitrogen inputs due to organic farming do not always lower nitrogen leaching from soil zone to the same extend compared with conventional farming. This can be explained by considerable lower crop yield and plant uptake of nitrogen. The baseline scenario regarding the liberalisation of the agricultural market (RAUMISTLB) leads to a considerable reduction of the nitrogen load in the Weiße Elster catchment. This is caused by a large reduction of arable land of $34 \%$ and pasture of $8.6 \%$ compared to the business as usual RAUMIS 2010 scenario. For both scenarios, the area weighted $(\mathrm{kg} / \mathrm{ha} \cdot \mathrm{a})$ reduction of the long-term mean nitrogen load is expressed as deviations from the status-quo sce- nario. There are large differences between both scenarios and a large spatial variation of nitrogen load reduction in each scenario with a maximum of $21 \mathrm{~kg} / \mathrm{ha} \cdot \mathrm{a}$ in two subcatchments after liberalisation of the agricultural market (RAUMIS-TLB). This is due to a large shift of arable land to pasture or fallow in connection with high nitrogen loads of the former arable land. The SWAT scenario for different shares of organic farming on the total agricultural land use shows a large variation of nitrogen load reduction within the Weiße Elster catchment.

Highest reduction of nitrogen loads can be observed in the upper part of the catchment. This reduction increases with an increase in organic farming. In contrast, in most lowland subcatchments, organic farming leads to a slight increase of nitrogen inputs in the river system (Fig. 6). It can be concluded that an overall increase of organic farming does not ensure a reduc-

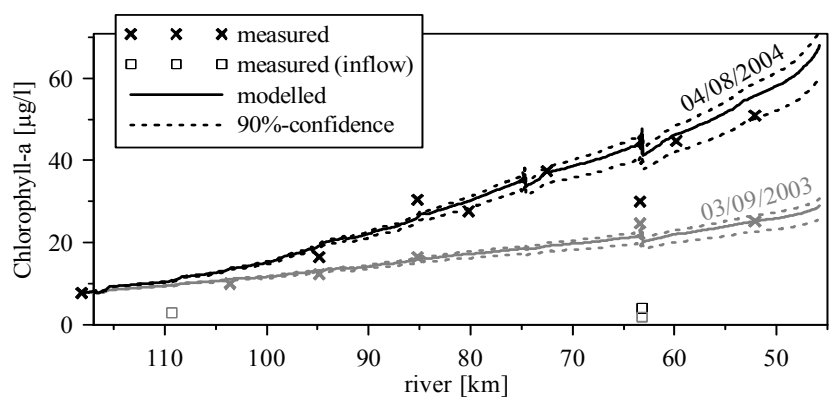

Figure 4

Measured and simulated concentrations of nitrate- $N$ in the selected river reach of the Weiße Elster (calibration mode)

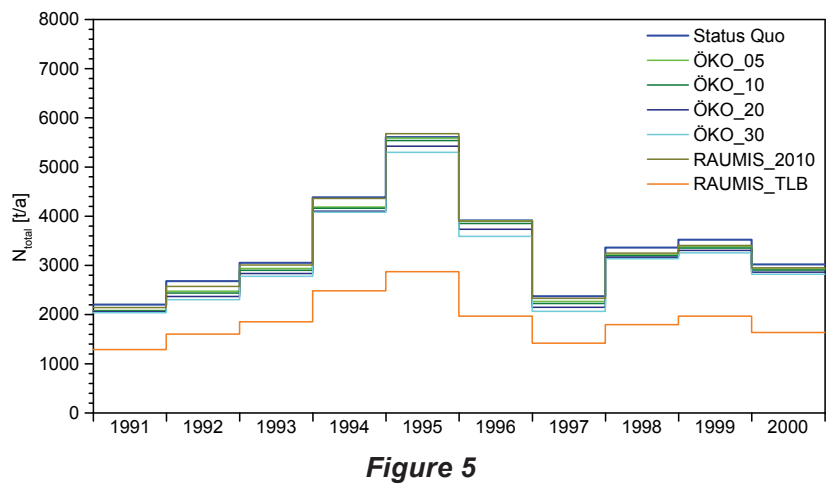

Nitrogen loads of SWAT scenarios at the discharge gauging station Gera-Langenberg

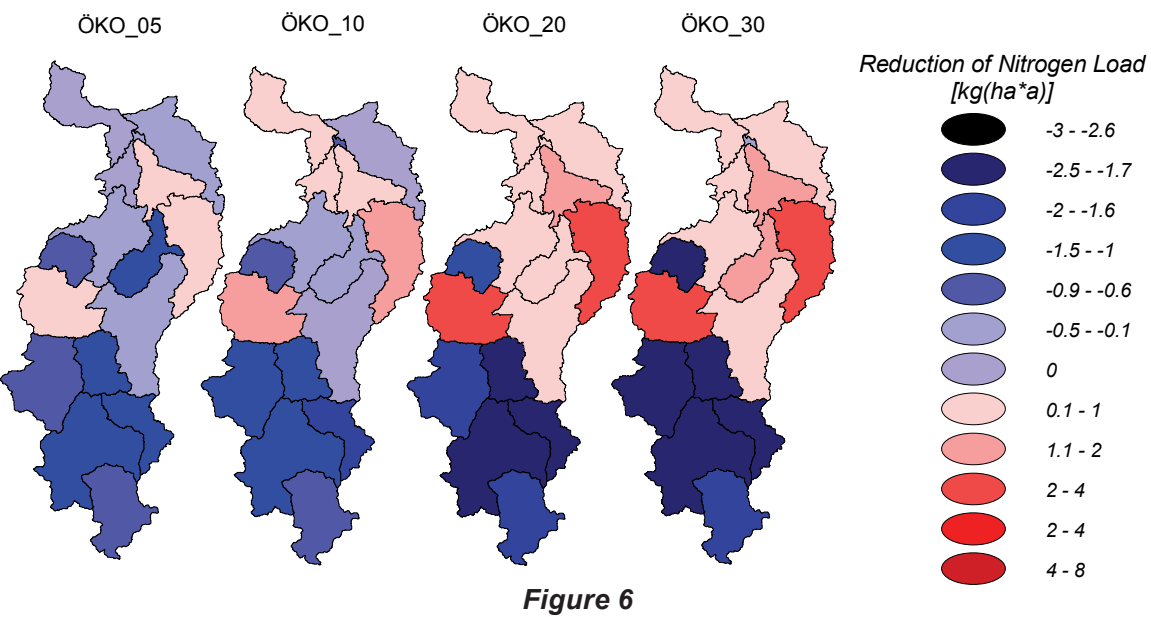

Nitrogen load changes of SWAT scenarios of organic farming compared with the status quo scenario 


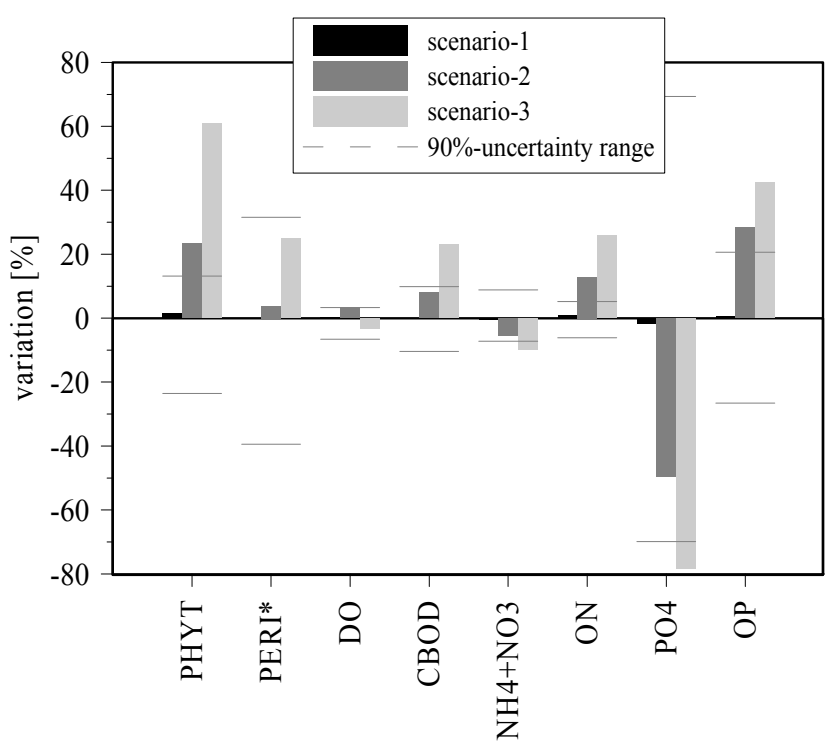

Figure 7

Percentage variation of WASP water quality variables at the outlet of the river section for three restoration scenarios (after Wagenschein and Rode, 2008)

tion of nitrogen leaching form agricultural land. Site specific characteristics like local to regional climate conditions and soil type distribution have to be taken into account. A more promising strategy seems to be an appropriate adjustment of the crop rotation at site specific locations. Of course this is also true for organic farming land-use practices.

\section{Impact of river restoration and river morphology on nitrogen retention}

The effect of the shape of the river cross section characterised by the sinuosity, the w/d-ratio and the Mannings coefficient on nitrogen concentrations was analysed by sensitivity analyses. The simulation study shows, that sinuosity has the strongest effect on all model variables. The influence of the w/d-ratio is lower and the effect of the Mannings coefficient is negligible. Furthermore, the elasticity of the model variables is varying: the effect of sinuosity is very strong for the components of autotrophic biomass. This accounts for a rise in the residence time and an increase of settling surface for periphyton. For the inorganic nitrogen the elasticity is lower because it is affected by several divergent processes. The most significant processes are that:

- The assimilation of nitrogen increases with increase in autotrophic biomass

- Nitrogen retention by benthic denitrification increases with increase in sediment surface. The elasticity of the inorganic phosphorus is comparably higher. The main reason is that its concentrations are quite low. This results in a higher sensitivity in contrast to autotrophic growth.

Three morphological scenarios were examined. They are characterised by deviating spatial intensities and combinations of restoration measures. River restoration Scenario 1 (municipal river maintenance program) has nearly no effect on the model variables (Fig. 7). River restoration Scenario 2, which assumes river channel restoration for unrestricted reaches, shows larger changes of inorganic nitrogen concentration (NH4+, NO3) compared to Scenario 1. Nitrogen concentrations decrease by $5.4 \%$ at the end of the $70.6 \mathrm{~km}$ river section. This can be explained by an increase of the autotrophic biomass (PHYT and PERI) and enhanced retention due to benthic denitrification.

River restoration Scenario 3 (hypothetical scenario) results in a decrease of inorganic nitrogen of $9.9 \%$, which is caused by an increase of the water-sediment interface. The removal of the weirs results in an increase of flow velocity and a corresponding decrease of residence time. This leads to a decrease of nitrogen turnover by about $3 \%$ compared to the present state.

The reduction of inorganic phosphorus $\left(\mathrm{PO}_{4}-\mathrm{P}\right)$ is more significant compared to nitrogen. This can mainly be attributed to the growth of phytoplankton and periphyton. As a result the organic phosphorus (OP) increases. The larger change of inorganic phosphorus in comparison to inorganic nitrogen can be explained by quite low concentrations $\left(<0.03 \mathrm{mg} \mathrm{PO}_{4} / \ell\right)$ in the present state. Furthermore $90 \%$ confidence limits were often larger than the predicted effect of the measure; this was especially true for the Scenarios 1 and 2. The assessment of these results has to take into account that the baseline scenario covers a time period of two weeks of summer conditions. For winter periods the nutrient concentration changes would be smaller because of lower biomass of algae and lower denitrification rates. Hence, the mean annual changes probably would be smaller too. The effect of the most feasible measures on the concentration of inorganic nitrogen, which are realised in river restoration Scenario 2, is quite low. Generally, the positive effects of rehabilitation measures on nutrient concentrations might be larger in small rivers compared to large rivers because of the larger w/d-ratio and a more intensive exchange between the water body and the hyporheic zone.

\section{Conclusions}

Within the HELP project a methodological approach for the implementation of the program of measures of the European WFD was developed and the use of water quality models for the impact assessment was demonstrated for the 4th order Weiße Elster catchment in central Germany. From the modelling study using SWAT it can be concluded that the investigated organic farming scenarios do not ensure a considerable reduction of high nitrogen loading from agricultural land of the studied catchment. Only the scenario on liberalisation of the agricultural market leads to a considerable reduction of nitrogen loads due to large reduction of agricultural land use of $42.6 \%$. The scenario analysis shows that sufficient reductions of nitrogen loads with respect to the ambitious goals of the European WFD can only be achieved with a considerable change of agricultural land use.

With regard to the river water quality modelling study it can be concluded that the impact of the most feasible measures on the concentration of inorganic nitrogen, which are realised in the river restoration Scenario 2, is quite low. Little effect on the yearly mean of inorganic phosphorus is also expected. The reason for that is that the autotrophic assimilation is low and the substance regimes between sediments and the water column are on average balanced, since the seasonal dependence of fixation through sorption or mobilisation by desorption or erosion is preponderant.

The parameter uncertainties are high and sometimes larger than the effect of the investigated river restoration management scenarios. The case study shows that easily applicable measures for the reduction of diffuse nutrient (especially nitrogen) loads may not be sufficient to reach the goal of a good water quality status requested by European WFD. 


\section{Acknowledgement}

This study was supported by the German Federal Ministry of Education and Research (BMBF) and European Union financed project 'Harmonised techniques and representative river basin data for assessment and use of uncertainty information in integrated water management' (HarmoniRib).

\section{References}

AMBROSE RB, WOOL TA and MARTIN JL (1993) The Water Quality Simulation Program, WASP5: Model Theory, User's Manual, and Programmer's Guide. US Environmental Protection Agency, Athens, GA, USA.

ARNOLD JG, WILLIAMS JR, SRINIVASAN R, KING KW and GRIGGS RH (1994) Soil and Water Assessment Tool. USDA, Agricultural Research Service, Grassland, Soil and Water Research Laboratory, Temple, TX 76502, USA.

DOHERTY J (2004) PEST - Model Independent Parameter Estimation. (5th edn. of User Manual) Watermark Numerical Computing, Brisbane, Australia.

EUROPEAN PARLIAMENT (2000) Directive 2000/60/Ec of the European parliament and of the council of 23 October 2000 establishing a framework for community action in the field of water policy. Official Journal of the European Communities L 357 22/12/2000. 72 pp.

GÖMANN H, KREINS P and JULIUS P (2003) Regionalisierung des makroskaligen Angebotsverhaltens landwirtschaftlicher Landnutzer im Elbeeinzugsgebiet bei Szenarien zu Klima- und Agrarmarktänderungen. Endbericht des Teilvorhabens zum GLOWA-Elbe-Projekt: „Integrierte Analyse der Auswirkungen des Globalen Wandels auf die Umwelt und die Gesellschaft im Elbegebiet." Forschungsgesellschaft für Agrarpolitik und Agrarsoziologie e.V., Bonn.

KRYSANOVA V and HABERLANDT U (2002) Assessment of nitrogen leaching from arable land in large river basins. Part I. Simu- lation experiments using a process-based model. Ecol. Model. 150 255-275.

MARKS R, MÜLLER MJ, LESER H and KLINK H-J (eds.) (1992) Anleitung zur Bewertung des Leistungsvermögens des Landschaftshaushaltes. Vol. Band 229. Selbstverlag des Zentralausschusses für deutsche Landeskunde, Trier, Germany.

NASH J and SUTCLIFFE J (1970) River flow forecasting through conceptional models. Part I - a discussion of principles. J. Hydrol. 10 282-290.

OMLIN M and REICHERT P (1999) A comparison of techniques for the estimation of model prediction uncertainty. Ecol. Model. 115 45-59.

POTTGIESSER T and HALLE M (2004) Concluding Work on the River Typology according to the Demands of the European Water Framework Directive (WFD). Project Report. Umweltbüro Essen, Germany (in German).

REICHERT P and VANROLLEGHEM P (2001) Identifiability and uncertainty analysis of the River water Quality Model No. 1. Water Sci. Technol. 43 (7) 329-338.

SHANAHAN P and ALAM M.M (2001) WASP Version 5.2, Maine Department of Environmental Protection.

VAN GRIENSVEN A, FRANCOS A and BAUWENS W (2002) Sensitivity analysis and auto-calibration of an integral dynamic model for river water quality. Water Sci. Technol. 45 (5) 321-328.

WAGENSCHEIN D and RODE M (2008) Modelling the impact of river morphology on nitrogen retention - A case study of the Weiße Elster River (Germany). Ecol. Model. 211 224-232.

WAGENSCHEIN D (2006) Einfluss der Gewässermorphologie auf die Nährstoffretention - Modellstudie am Beispiel der mittleren Weißen Elster. Ph.D. Thesis, Brandenburgisch Technische Universität Cotbus, Germany.

WARWICK JJ (1999) Enhancement of the hydrodynamic model DYNHYD. Commented source code.

WILLMOTT CJ (1982) Some comments on the evaluation of model performance. Bull. Am. Meteorol. Soc. 63 1309-1313. 